\title{
Metabolic syndrome at 6 weeks after delivery in a cohort of pre-eclamptic and normotensive women
}

\author{
P Ntlemo, ${ }^{1}$ BSc (Med Sci), MB ChB; T Cronje, ${ }^{2}$ MSc (Mathematical Statistics); \\ P Soma-Pillay, ${ }^{1,3}$ MB ChB, Dip Obst (SA), FCOG (SA), MMed (O et G), PhD \\ ${ }^{1}$ Department of Obstetrics and Gynaecology, School of Medicine, Faculty of Health Sciences, University of Pretoria and Steve Biko Academic \\ Hospital, Pretoria, South Africa \\ ${ }^{2}$ Department of Statistics, Faculty of Natural and Agricultural Sciences, University of Pretoria, South Africa \\ ${ }^{3}$ South African Medical Research Council Maternal and Infant Health Care Strategies Unit, Department of Obstetrics and Gynaecology, \\ School of Medicine, Faculty of Health Sciences, University of Pretoria, South Africa
}

Corresponding author: P Soma-Pillay (priya.somapillay@up.ac.za)

\begin{abstract}
Background. The association between pre-eclampsia and the subsequent development of metabolic syndrome has not been well documented in low- and middle-income countries.

Objectives. To compare the prevalence of metabolic syndrome at 6 weeks after delivery among women with pregnancies complicated by pre-eclampsia with that in a normotensive, low-risk control group in an urban South African (SA) setting.

Methods. This was a prospective cohort study at two tertiary-level hospitals and one district-level hospital in Pretoria, SA. Women were recruited after delivery and were followed up 6 weeks later to confirm or exclude the diagnosis of metabolic syndrome.

Results. Metabolic syndrome was diagnosed in 48/150 women with pregnancies complicated by pre-eclampsia (32.0\%), compared with $33 / 150(22.0 \%)$ of the control group $(p=0.05)$.

Conclusions. Women who developed pre-eclampsia during pregnancy had an increased chance of metabolic syndrome being diagnosed 6 weeks after delivery. Guidelines should be developed to identify women with cardiometabolic risk, so that interventions may be implemented to modify this risk before and after pregnancy.
\end{abstract}

S Afr Med J 2021;111(4):350-354. https://doi.org/10.7196/SAMJ.2021.v111i4.15349

Metabolic syndrome consists of a cluster of risk factors that in combination predispose an individual to the risk of diabetes mellitus, cardiovascular disease and cardiovascular-related mortality. The diagnosis is confirmed by the presence of three out of five of the following risk factors: hyperglycaemia, elevated triglycerides, reduced high-density lipoprotein (HDL), increased waist circumference and high blood pressure (BP). ${ }^{[1]}$ Pregnancy is considered an atherogenic state resulting in a significant increase in serum triglycerides, total cholesterol, low-density cholesterol and HDL. Chiang et al. ${ }^{[2]}$ found that in low-risk pregnancies, the progressive increase in lipid concentration during pregnancy recovered to near normal after delivery, and that most other atherogenic risk factors were independent of gestation..$^{[2]}$ The prevalence of metabolic syndrome in women is $\sim 22 \%$, but varies between different races, age groups and socioeconomic status. ${ }^{[3]}$ The incidence of metabolic syndrome in women of childbearing age in South Africa (SA) varies from 9\% to $42 \%{ }^{[4]}$

Pre-eclampsia is a pregnancy-specific disorder characterised by the presence of hypertension and proteinuria or end-organ dysfunction after 20 weeks' gestation. ${ }^{[5]}$ The pathophysiology involves both fetal and placental factors that in early pregnancy contribute to abnormalities of the maternal and placental vasculature. These changes contribute to the development of hypoxia and ischaemia of the placenta, and subsequent release by the placenta of anti-angiogenic factors into the maternal circulation causing maternal systemic endothelial dysfunction. ${ }^{[6]}$ This process may lead to hypertension and other disease manifestations such as haematological, cardiac, neurological, pulmonary, hepatic and renal dysfunction. However, the trigger for the abnormal placental development and subsequent cascade of events remains unknown. It has been hypothesised that immune factors such as natural killer cell abnormalities, oxidative stress and genetic factors are the major triggers of placental dysfunction. ${ }^{[7]}$

The association between pre-eclampsia and the subsequent diagnosis of metabolic syndrome has been widely reported in developed countries. ${ }^{[8-11]}$ However, this association has not been well documented in low- and middle-income countries such as SA. The potential mechanism linking pre-eclampsia to the postpartum development of metabolic syndrome is not well understood. Physiological changes in pregnancy such as changes in weight, insulin resistance, oxidative stress and atherogenic dyslipidaemia are exaggerated in pregnancies complicated by pre-eclampsia. Oxidative stress plays a role in atherosclerosis. The oxidative stress theory of pre-eclampsia involves the hypothesis that abnormal placentation and dyslipidaemia result in release of free radicals that damage vascular endothelium. ${ }^{[12]}$ Endothelial damage further causes increased vascular sensitivity to pressor effects and decreased formation of vasodilators, leading to an increase in total peripheral resistance. It is postulated that these changes possibly contribute to long-term ongoing pathophysiology.

\section{Objectives}

To compare the prevalence of metabolic syndrome at 6 weeks after delivery among women with pregnancies complicated by preeclampsia with that in a normotensive, low-risk control group. 


\section{Methods}

This was a prospective cohort study performed at two tertiary-level hospitals (Steve Biko Academic Hospital and Kalafong Provincial Tertiary Hospital) and one district-level hospital (Tshwane District Hospital) in Pretoria, SA, between 1 February 2019 and 30 April 2020. Pre-eclamptic women were identified on the daily morning ward rounds at the two tertiary hospitals. The control group of lowrisk, normotensive women was selected randomly by counting every third patient from the daily list of deliveries of low-risk women at the district hospital. Women who agreed to participate in the study were requested to follow up at 1 week and 6 weeks after delivery for postnatal check-up visits. The 6-week postnatal visit consisted of the routine obstetric examination as well as an additional evaluation to confirm or exclude the diagnosis of metabolic syndrome.

Hypertension was defined as a systolic BP $>140 \mathrm{mmHg}$ and/or a diastolic $\mathrm{BP}>90 \mathrm{mmHg}$. Pre-eclampsia was diagnosed in accordance with the International Society for the Study of Hypertension in Pregnancy guideline. ${ }^{[13]}$ Metabolic syndrome was diagnosed using the International Diabetes Federation classification, ${ }^{[1]}$ i.e. the presence of three out of five of the following: (i) $\mathrm{BP} \geq 130 / 85 \mathrm{mmHg}$; (ii) waist circumference $>80 \mathrm{~cm}$; (iii) fasting glucose $>5.6 \mathrm{mmol} / \mathrm{L}$; (iv) triglycerides $>1.7 \mathrm{mmol} / \mathrm{L}$; and $(v) \mathrm{HDL}<1.29 \mathrm{mmol} / \mathrm{L}$. BP was recorded in a sitting, relaxed position with both arms resting on an arm-rest chair. Waist circumference was measured using a tape measure and recorded in centimetres. This was done as follows: the anterior superior iliac spine and then the lowest part of the costal margin were palpated, and the distance between the two points was the point where the abdominal circumference was measured. For most women this point was at the level of the umbilicus. The remainder of the parameters (glucose, triglycerides and HDL levels) were determined by drawing blood, which was sent to the laboratory for determination.

Descriptive statistics in the form of means and standard deviations were utilised, as well as frequencies and proportions for categorical variables. Shapiro-Wilk tests were performed to determine whether the data were normally distributed, followed by the non-parametric Mann-Whitney $U$-test, or $\chi^{2}$ tests for categorical variables, which investigated whether significant differences existed between the two groups. All tests of significance were performed at a 5\% level of significance. Ethical approval for the study was obtained from the University of Pretoria Research Ethics Committee (ref. no. 10/2019).

\section{Results}

One hundred and fifty women were recruited to the study group and 163 women to the control group. There was no loss to follow-up in the pre-eclamptic group, while 13 women were lost to follow-up in the control group. Data were therefore available for 150 women in each group. One hundred and twenty-eight women (85.3\%) in the pre-eclamptic group developed early-onset disease, prior to 34 weeks, while 11 women were known to have had chronic hypertension before they became pregnant. Metabolic syndrome was diagnosed in 48 women (32.0\%) in the pre-eclamptic group and $33(22.0 \%)$ in the control group $(p=0.05)$. The demographic data of the study population are shown in Table 1. Table 2 compares the results of metabolic syndrome parameters of the two groups at 6 weeks after delivery. Hypertension was diagnosed in 49 pre-eclamptic women $(32.7 \%)$ at the 6-week postnatal visit, compared with 34 controls (22.7\%).

Eighty-one women were diagnosed with metabolic syndrome after delivery. More than $80 \%(n=65)$ of women with confirmed metabolic syndrome at 6 weeks after delivery in both the pre-eclamptic and control groups had raised BP, waist circumference and triglycerides.
HDL levels were low in $18.8 \%(n=9)$ of women diagnosed with metabolic syndrome in the pre-eclamptic group compared with $36.4 \%(n=12)$ in the control group, while fasting glucose levels were raised in $6.3 \%(n=3)$ of women in the pre-eclamptic group compared with $15.2 \%(n=5)$ in the control group.

\section{Discussion}

Metabolic syndrome is an important contributor to the growing burden of non-communicable diseases in SA. In our study, the prevalence of metabolic syndrome 6 weeks after delivery was $32.0 \%$ in the pre-eclamptic group compared with $22.0 \%$ in the control group ( $p=0.05$ ). This finding is similar to the prevalence of $35 \%$ reported in a prospective cohort study of hypertensive pregnancies in Kenya. ${ }^{[14]}$ Women in developed countries have a $15-20 \%$ risk of being diagnosed with metabolic syndrome after pregnancies complicated by pre-eclampsia. ${ }^{[8,15,16]}$ Women with low-risk pregnancies in our study demonstrated an equivalent risk to pre-eclamptic women in developed countries. This study therefore also highlights the risk of future cardiovascular disease in a young parous SA urban population. Thirty-eight women $(25.3 \%)$ who were normotensive during pregnancy were diagnosed with hypertension after delivery. The South African National Health and Nutrition Examination Survey found that $8.8 \%$ of SA women in the age group 15 - 24 years were hypertensive, $18.1 \%$ in the 25 - 34-year age group and $41.1 \%$ in the 35 - 44-year age group. ${ }^{[17]}$ It is possible that some women in our control group were hypertensive prior to pregnancy but had normal blood pressure readings during pregnancy owing to the physiological lowering of blood pressure during pregnancy.

Women were recruited to our study during pregnancy, and we did not have any information regarding the prevalence of metabolic syndrome prior to pregnancy. An important question is whether risk factors for metabolic syndrome increase pre-eclampsia risk, or whether pre-eclampsia predisposes to metabolic syndrome in later life. Scholten et al. ${ }^{[18]}$ performed a retrospective analysis of 1297 women with a history of pre-eclampsia who had prior screening for cardiovascular and prothrombotic risk factors at a pre-conception clinic. Metabolic syndrome was present in $15 \%$ of women who were subsequently diagnosed with pre-eclampsia. In the HUNT study in Norway, 3225 women were followed up for 20 years. ${ }^{[19]}$ Cardiovascular markers were compared before and following normal and pre-eclamptic pregnancies. Most but not all risk was present before the pre-eclamptic pregnancy. The American Heart Association has emphasised that the evaluation of cardiovascular risk for women should include a pregnancy history and that pre-eclampsia should be considered a risk factor. ${ }^{[20]}$

More than $80 \%$ of women with confirmed metabolic syndrome at 6 weeks after delivery had raised BP, waist circumference and triglyceride levels. HDL levels were low in $18.8 \%$ of women diagnosed with metabolic syndrome in the pre-eclamptic group and in $36.4 \%$ in the control group. Data from several African regions have demonstrated that some components of the metabolic syndrome, such as high waist circumference and low HDL levels, are the most prevalent components, while other studies have reported lower triglyceride levels in African populations. ${ }^{[21-23]}$ With the exception of glucose values, all components for the diagnosis of metabolic syndrome were deranged in our cohort of women diagnosed with metabolic syndrome. Ray et al. ${ }^{[24]}$ found that women with features of metabolic syndrome before pregnancy have a higher graded risk of placental dysfunction during pregnancy. They found a progressive increase in the risk of placental dysfunction in women with one (adjusted odds ratio (aOR) 3.1; 95\% confidence interval (CI) 3.0 - 3.1), two (aOR 5.5; 95\% CI 5.2 - 5.8), or three or 
Table 1. Demographic data for the study population at delivery

\begin{tabular}{|c|c|c|c|}
\hline Characteristics & Pre-eclamptic group $(N=150)$ & Control group $(N=150)$ & $p$-value \\
\hline Age (years) & & & $<0.01$ \\
\hline Mean (SD) & $25.9(5.2)$ & $23.4(5.7)$ & \\
\hline Range & $18-40$ & $15-42$ & \\
\hline \multicolumn{4}{|l|}{ Race, $n(\%)$} \\
\hline Black African & $133(88.6)$ & $129(86.0)$ & \\
\hline Coloured & $11(7.3)$ & $14(9.3)$ & \\
\hline White & $4(2.7)$ & $2(1.3)$ & \\
\hline Indian & $2(1.3)$ & $5(3.3)$ & \\
\hline \multicolumn{4}{|l|}{ Parity } \\
\hline Median (IQR) & $2(1-2)$ & $1(1-2)$ & \\
\hline Range & $0-6$ & $0-5$ & \\
\hline \multicolumn{4}{|c|}{ Timing of delivery (weeks), $n$ (\%) } \\
\hline$<34$ & $122(81.3)$ & 0 & \\
\hline $34-37$ & $20(13.3)$ & $13(8.7)$ & \\
\hline$>37$ & $8(5.3)$ & $137(91.3)$ & \\
\hline Birth weight (g) & & & $<0.01$ \\
\hline Mean (SD) & $1830.6(570.1)$ & $3079.8(459.1)$ & \\
\hline Range & $1200-3750$ & $2140-4050$ & \\
\hline \multicolumn{4}{|c|}{ Blood pressure $(\mathrm{mmHg})$} \\
\hline Systolic & & & $<0.01$ \\
\hline Mean (SD) & $152.4(9.4)$ & $120.2(6.9)$ & \\
\hline Range & $138-184$ & $100-138$ & \\
\hline Diastolic & & & $<0.01$ \\
\hline Mean (SD) & $96.7(6.1)$ & $71.7(8.6)$ & \\
\hline Range & $75-114$ & $56-90$ & \\
\hline
\end{tabular}

Table 2. Parameters used for the diagnosis of metabolic syndrome at 6 weeks after delivery

\begin{tabular}{|c|c|c|c|}
\hline Parameter & Pre-eclamptic group & Control group & $p$-value \\
\hline \multicolumn{4}{|l|}{ Blood pressure $(\mathrm{mmHg})$} \\
\hline Systolic & & & 0.30 \\
\hline Mean (SD) & $132.3(12.3)$ & $130.5(11.3)$ & \\
\hline Range & $115-158$ & $110-162$ & \\
\hline Diastolic & & & 0.02 \\
\hline Mean (SD) & $80.6(10.3)$ & $78.0(10.0)$ & \\
\hline Range & $60-99$ & $60-104$ & \\
\hline Waist circumference $(\mathrm{cm})$ & & & 0.44 \\
\hline Mean (SD) & $79.3(7.0)$ & $78.8(6.1)$ & \\
\hline Range & $64-97$ & $67-96$ & \\
\hline Fasting glucose $(\mathrm{mmol} / \mathrm{L})$ & & & $<0.01$ \\
\hline Mean (SD) & $4.2(0.8)$ & $4.4(0.7)$ & \\
\hline Range & $2.8-8.0$ & $3.0-6.9$ & \\
\hline Triglycerides $(\mathrm{mmol} / \mathrm{L})$ & & & 0.14 \\
\hline Mean (SD) & $1.4(0.5)$ & $1.5(0.5)$ & \\
\hline Range & $0.5-2.7$ & $0.7-3.1$ & \\
\hline $\mathrm{HDL}(\mathrm{mmol} / \mathrm{L})$ & & & 0.12 \\
\hline Mean (SD) & $1.7(0.6)$ & $1.8(0.4)$ & \\
\hline Range & $0.5-3.5$ & $0.8-3.0$ & \\
\hline
\end{tabular}

four (aOR 7.7; 95\% CI 6.7 - 8.9) features of the metabolic syndrome, compared with none.

Hypertension is a major contributor to the growing burden of non-communicable diseases, and black Africans, particularly young women, appear to be most affected by this increasing public health problem. ${ }^{[25]}$ Compared with other racial groups, black African women are at greater risk of developing pre-eclampsia with severe features. ${ }^{[26]}$ A large proportion of black SA women live in urban areas, where rates of metabolic syndrome are reported to be $\sim 13 \%$ higher than in rural areas. ${ }^{[27]}$ It is believed that these differences are largely due to 
the increased prevalence of obesity associated with 'westernisation' of dietary intake and changes in lifestyle. ${ }^{[27]}$ Studies in SA have further shown that dietary fat intake has increased significantly over the past 5 decades. ${ }^{[22]}$ The prevalence of metabolic syndrome is consistently higher in black African females than in males. ${ }^{[4]}$ The high prevalence of metabolic syndrome in both the pre-eclamptic and control groups in our study suggests that pregnancy and other epidemiological factors such as female gender, ethnicity and urbanisation probably play a role in the development of metabolic syndrome in SA urban women. Women diagnosed with metabolic syndrome are at increased risk of future complications such as stroke, myocardial infarction and type 2 diabetes. Furthermore, the COVID-19 pandemic has shown that cardiometabolic syndrome is a risk factor for worse outcomes. Epidemiological data from $>72000$ patients in mainland China demonstrated an overall case fatality rate from COVID-19 of $2.3 \%$, but the case fatality rate for patients with hypertension was $6 \% .{ }^{[28]}$ Individuals with COVID-19 infection with other comorbidities are at increased risk of severe pneumonia, uncontrolled inflammatory response and hypercoagulability.

Maternal mortality audits have traditionally been used as an indicator of obstetric care in several countries. Maternal mortality is a complex factor that is influenced by a woman's socioeconomic and health status as well as access to care and delivery of services. The World Health Organization defines maternal mortality as the death of a woman while pregnant or within 42 days of termination of pregnancy, irrespective of site or duration of pregnancy. ${ }^{[29]}$ The 42 -day limit reflects the belief that consequences arising from pregnancy cease after 42 days. The present study has shown that even in low-risk, normotensive women, ill health may persist at and beyond 42 days after delivery. Current guidelines acknowledge the increased cardiometabolic risk associated with pregnancies complicated by pre-eclampsia, but guidance on specific intervention is lacking. Based on these results, surveillance should continue beyond the 6-week postpartum period. Strategies should be developed to identify women at risk of chronic conditions. Interventions such as health education, lifestyle modification and pharmacotherapy should be explored further. The California Teachers Study was a prospective cohort study that included $>80000$ women. ${ }^{[30]}$ Approximately $5 \%(n=4070)$ of these women with prior hypertensive disorders of pregnancy had increased long-term stroke risk, which was reduced by aspirin use. ${ }^{[30]}$ Hofmeyr et al ${ }^{[31]}$ have shown that calcium supplementation in women with deficient dietary calcium may be beneficial in lowering blood pressure in the long term.

\section{Study strengths and limitations}

The strength of this study is that it is the first study to determine the prevalence of metabolic syndrome in a young urban SA female population following pregnancy. The limitation is that all women were seen for the first time during pregnancy. The prevalence of metabolic syndrome prior to pregnancy is unknown. The majority of women in the pre-eclamptic group developed early-onset disease; the observation of postpartum metabolic syndrome among women with pre-eclampsia may therefore be a feature of this subgroup of women. Further research involving follow-up of women prior to and after pregnancy is required. More than $85 \%$ of women in both the pre-eclamptic and control groups were black African. The numbers of women of other population groups were small, and it is possible that the results are not reflective of women in all population groups, as lifestyle and diet may differ. Further investigations to confirm or exclude the presence of cardiovascular disease were not performed. The follow-up time was also limited to 6 weeks postpartum, and a further follow-up 1 year after delivery would have been preferable.

\section{Conclusions}

Women who develop pre-eclampsia during pregnancy have an increased risk of being diagnosed with metabolic syndrome 6 weeks after delivery. The prevalence of metabolic syndrome in black African urban women who have uncomplicated low-risk pregnancies is $\sim 22 \%$, and it is even higher in women who have had pre-eclampsia. Given the severe long-term effects of the metabolic syndrome and the potential for altering its natural course by specific interventions, healthcare surveillance of black African women should continue beyond the 42-day suggested postpartum period.

Declaration. The research for this study was done in partial fulfilment of the requirements for PN's MMed (O et G) degree at the University of Pretoria.

Acknowledgements. None.

Author contributions. PN and PS-P designed the study and jointly wrote the manuscript. PN collected the data. TC was responsible for statistical analysis.

Funding. None.

Conflicts of interest. None.

1. Alberti KG, Zimmet P, Shaw J; for the IDF Edidemiology Task Force Consensus Group. The metabolic syndrome - a new worldwide definition. Lancet 2005;366(9491):1059-1062. https://doi.org/10.1016/ \$0140-6736(05)67402-8

2. Chiang AN, Yang ML, Hung JH, Chou P, Shyn SK, Ng TH. Alterations of serum lipid levels and their biological relevances during and after pregnancy. Life Sci 1995;56(26):2367-2375. https://doi. org/10.1016/0024-3205(95)00230-4

3. Von Versen-Hoeynck FM, Powers RW. Maternal-fetal metabolism in normal pregnancy and preeclampsia. Front Biosci 2007;12:2457- 2470. https://doi.org/10.2741/2247

Gradidge PJ, Crowther NJ. Review: Metabolic syndrome in black South African women. Ethn Dis 2017;2(2):189-198. https://doi.org/10.18865/ed.27.2.189

5oodley J, Soma-Pillay P, Buchmann E, Pattinson RC. Hypertensive disorders in pregnancy: 2019 national guideline. S Afr Med J 2019;109(3 Suppl 1):S3-S16. https://doi.org/10.7196/SAMJ.2019. v109i3.14104

6. Magee LA, Pels A, Helewa M. Diagnosis, evaluation and management of the hypertensive disorders of pregnancy. J Obstet Gynaecol Can 2014;36(5):416-441. https://doi.org/10.1016/s1701-2163(15)30588-0 . Osungbade KO, Olusimbo KI. Public health perspective of preeclampsia in developing countries: Implication for health system strengthening. J Pregnancy 2011;2011, article ID 481095. https://doi. $\mathrm{rg} / 10.1155 / 2011 / 481095$

8. Van Rijn BB, Nijdam ME, Bruinse HW. Cardiovascular disease risk factors in women with a history of early onset pre-eclampsia. Obstet Gynecol 2013;121(5):1040-1048. https://doi.org/10.1097/ Carly onset pre-ec

9. Mangos GJ, Spaan JJ, Pirabhahar S, Brown MM. Markers of cardiovascular disease risk after hypertension Mangos GJ, Spaan JJ, Pirabhahar S, Brown MM. Markers of cardiovascular disease risk after hype
in pregnancy. J Hypertens 2012;30(2):351-358. https://doi.org/10.1097/HJH.0b013e32834e5ac7

in pregnancy. J Hypertens 2012;30(2):351-358. https://doi.org/10.1097/HJH.0b013e32834e5ac7
10. Giguere Y, Charland M, Theriault S. Linking preeclampsia and cardiovascular disease later in life. Clin . Giguere Y, Charland M, Theriault S. Linking preeclampsia and cardiovascula
Chem Lab Med 2012;50(6):985-993. https://doi.org/10.1515/CCLM.2011.764

1. Forrest JC, Girouard J, Masse J. Early occurrence of metabolic syndrome and hypertension in pregnancy. . Forrest JC, Girouard J, Masse J. Early occurrence of metabolic syndrome and hypertension in
Obstet Gynecol 2005;105(6):1373-1380. https://doi.org/10.1097/01.aog.0000163252.02227.f8

Obstet Gynecol 2005;105(6):1373-1380. https://doi.org/10.1097/01.aog.0000163252.02227.f8
12. Rodie VA, Freeman DJ, Sattar N, Greer IA. Pre-eclampsia and cardiovascular disease: Metabolic syndrome of pregnancy? Atherosclerosis 2004;175(2):189-202. https://doi.org/10.1016/j. atherosclerosis.2004.01.038

13. Brown MA, Magee LA, Kenny LC, et al. The hypertensive disorders of pregnancy: ISSHP classification, diagnosis and management recommendations for international practice. Pregnancy Hypertens 2018;13:291-310. https://doi.org/10.1016/j.preghy.2018.05.004

14. Osoti AO, Page ST, Richardson BA, et al. Postpartum metabolic syndrome after gestational hypertension and preeclampsia, a prospective cohort study. Pregnancy Hypertens 2019;18:35-41. https://doi.org/10.1016/j.preghy.2019.08.088

15. Van Rijn BB, Nijdam ME, Bruinse HW, et al. Cardiovascular disease risk factors in women with a history of early-onset preeclampsia. Obstet Gynecol 2013;121(5):1040-1048. https://doi.org/10.1097/ AOG.0b013e31828ea3b5

16. Verbeek JHW, Hermes W, Breimer AY, van Rijn BB, Koenen SV, Mol BW. Cardiovascular disease risk factors after early-onset preeclampsia, late-onset preeclampsia and pregnancy-induced hypertension. Hypertension 2015;65(3):600-606. https://doi.org/10.1161/HYPERTENSIONAHA.114.04850

17. Berry KM, Parker W, Mchiza ZJ, Sewpaul R, Labadarios D, Rosen S, Stokes A. Quantifying unmet need for hypertension care in South Africa through a care cascade: Evidence from the SANHANES, 2011 2012. BMJ Glob Health 2017;2(3):e000348. https://doi.org/10.1136/bmjgh-2017-000348

18. Scholten RR, Hopman MTE, Sweep FCGJ, et al. Co-occurrence of cardiovascular and prothrombotic Scholten RR, Hopman MTE, Sweep FCG], et al. Co-occurrence of cardiovascular and prothrombotic
risk factors in women with a history of preeclampsia. Obstet Gynecol 2013;121(1):97-105. https://doi. risk factors in women with a history of

19. Romundstad PR, Magnussen EB, Smith GD, Vatten LJ. Hypertension in pregnancy and later Romundstad PR, Magnussen EB, Smith GD, Vatten LJ. Hypertension in pregnancy and later
cardiovascular risk: Common antecedents? Circulation 2010;122:579-584. https://doi.org/10.1161/
CIRCULATIONAHA.110.943407

20. Mocsa L, Benjamin EJ, Berra K, et al. Effectiveness-based guidelines for the prevention of cardiovascular disease in women - 2011 update: A guideline from the American Heart Association. cardiovascular disease in women - 2011 update: A guideline from the American He
Circulation 2011;123(11):1243-1262. https://doi.org/10.1161/CIR.0b013e31820faaf8

21. Crowther NJ, Norris SA. The current waist circumference cut-point used for the diagnosis of metabolic Crowther NJ, Norris SA. The current waist circumference cut-point used for the diagnosis of metabolic
syndrome in sub-Saharan African women is not appropriate. PLoS ONE 2012;7(11):48883. https://doi. syndrome in sub-Saharan African wo
org/10.1371/journal.pone. 0048883

22. Fezu L, Balkau B, Kengne AP, Sobngwi E, Mbanya JC. Metabolic syndrome in a sub-Saharan African setting: Central obesity may be the key determinant. Artherosclerosis 2007;193(1):70-76. https://doi. org/10.1016/j.atherosclerosis.2006.08.037 
23. Sumner A. Ethnic differences in triglyceride levels and high density lipoproteins lead to underdiagnosis of the metabolic syndrome in black children and adults. J Pediatr 2009;155(3):7-11. https://doi.org/10.1016/j. jpeds.2009.04.049

24. Ray JG, Vermeulen MI, Schull MI, McDonald S, Redelmeier DA. Metabolic syndrome and the risk of placental dysfunction. J Obstet Gynaecol Can 2005;27(12):1095-1101. https://doi.org/10.1016/S17012163(16)30391-7

25. Sliwa K, Ojji D, Bachelier K, Bohm M, Damasceno A, Stewart S. Hypertension and hypertensive heart disease in African women. Clin Res Cardiol 2014;103:515-523. https://doi.org/10.1007/s00392-014-0660-2 26. Nakimuli A, Chazara O, Byamugisha J, Elliot A, Kaleebu P, Mirembe F, Moffett A. Pregnancy, parturition and preeclampsia in women of African ancestory. Am J Obstet Gynecol 2014;210(6):510-520. https://doi. org/10.1016/j.ajog.2013.10.87

27. Gradidge PJ, Crowther NJ, Chirwa ED, et al. Patterns, levels and correlates of self-reported physical activity in urban black Soweto women. BMC Public Health 2014;14:934. https://doi.org/10.1186/1471-2458-14-934

28. Bansal R, Gubbi S, Muniyappa R. Metabolic syndrome and COVID-19: Endocrine-immune-vascular interactions shapes clinical course. Endocrinology 2020;161(10):bqaa12. https://doi.org/10.1210/endocr/ bqaall
29. World Health Organization. Evaluating the quality of care for severe pregnancy complications: The WHO near-miss approach for maternal health. 2011. https://www.who.int/reproductivehealth/ publications/monitoring/9789241502221/en/ (accessed 5 March 2021).

30. Miller EC, Lakshminarayan K, Zhong C, et al. Aspirin reduces long-term stroke in women with prior hypertensive disorders of pregnancy. Neurology 2019;92(4):e305-e316. https://doi.org/10.1212 WNior hypertensive disord

31. Hofmeyr GJ, Duley L, Atallah A. Dietary calcium supplementation for prevention of pre-eclampsia and related problems: A systematic review and commentary. Br J Obstet Gynaecol 2007;114(8):933-
and and related problems: A systematic review and com $/ /$ doi.org/10.1111/j.1471-0528.2007.01389.x

Accepted 3 November 2020 